\title{
3D printed horn antenna using direct metal laser melting technique for millimetre wave applications
}

Muataz W. Sabri, N. A. Murad, M. K.A. Rahim, F. Zubir

School of Electrical Engineering, University Technology Malaysia, Malaysia

\begin{tabular}{|c|c|}
\hline Article Info & ABSTRACT \\
\hline Article historys: & \multirow{10}{*}{$\begin{array}{l}\text { A 3D printed horn antenna at ka-band is presented in this paper. The horn } \\
\text { antenna is well known for high gain performance. The performance of the horn } \\
\text { antenna manufactured using 3D printed technology is investigated in this } \\
\text { work. The horn is designed based on WR-28 waveguide standard. } \\
\text { The proposed horn is simulated by computer simulation technology (CST) } \\
\text { software and fabricated using 3D printing direct metal laser melting technique. } \\
\text { The 3D printing technique gives the antenna an advantage of being not just } \\
\text { rapid manufactured but also low-cost and lightweight. However, several works } \\
\text { reported on 3D printed devices highlight the effects of surface roughness and } \\
\text { dimensional tolerance on the performances. Therefore, the printed horn is } \\
\text { profiled to correlate the surface roughness and dimension tolerance towards } \\
\text { the performance. The printed horn is measured using standard VNA. } \\
\text { The results showed that the measured performance agreed fairly with the } \\
\text { simulation with directive radiation pattern at } 15 \mathrm{dBi} \text { gain. The printed horn has } \\
\text { a weight of less than } 130 \mathrm{~g} \text { and considerably working at Ka band regardless of } \\
\text { the surface roughness resulted from the fabrication process. }\end{array}$} \\
\hline Received Mar 27, 2019 & \\
\hline Revised May 6, 2019 & \\
\hline Accepted May 26, 2019 & \\
\hline Keywords: & \\
\hline $3 \mathrm{D}$ printing & \\
\hline CST & \\
\hline DMLM & \\
\hline Horn antenna & \\
\hline Milimetre wave & \\
\hline
\end{tabular}

Copyright (C) 2019 Institute of Advanced Engineering and Science. All rights reserved.

\section{Corresponding Author:}

Muataz W. Sabri,

School of Electrical Engineering,

University Technology Malaysia,

Jalan Iman, 81310 Skudai, Johor, +6075533333, Malaysia.

Email: wssmuataz2@live.utm.my

\section{INTRODUCTION}

Nowadays, the 3D printing technology is adopted for the production of high-resolution machining, reduced fabrication costs, and high-performance millimetre waves ( $\mathrm{mm}$-Wave) passive and active devices. Additive manufacturing (AM) is also well known as $3 \mathrm{D}$ printing process has the merits of eco-environment friendly technology, low power consuming, low cost, and high flexibility of fabricating complex structures [1]. However, the three main drawbacks of 3D printing technology are listed as followed; the surface roughness, high dimensional tolerance, and the weak mechanical structure [2].

There are different techniques in 3D printing technology that may cater for different materials. The techniques can be categorised as fused deposition modelling (FDM), stereolithography apparatus (SLA), selective laser melting (SLM), and electron beam melting technology (EBM) [3-5]. Recently, a new technique is introduced in 3D printing [6] based on laser melting metal powder. To the authors' knowledge, the fabrication of passive mm-Wave devices using this technique is not yet presented. Different technique can either print non-metal or metal structure. Most common non-metal material is ABS. Passive devices printed using ABS normally made into parts before metal coated and assembled, resulting in a low cost and low body mass. The metal 3D printing process can print a passive device in one full piece for certain dimensions. Both non-metal and metal print are suffered from surface roughness and low dimensional tolerance, while electrostatic discharge (ESD) and structure weakness are the main concerns in non-metal 3D printing process. 
The horn antenna is one of the most common types of antenna used in microwave devices. It is commonly used in the fields of radar system, satellite communications, feeding for reflector antenna, and as a standard measurement part for calibration process, due to its simplicity, high gain, wide bandwidth, high directivity, and easy to fabricate [7]. Normally, the horn antenna is manufactured using traditional manufacturing techniques including $\mathrm{CNC}$ machining [8]. In mm-Wave horn antenna manufacturing, the demand for light weight, low cost, and high performance are needed. CNC is widely known in fabricating low frequency horns. CNC printing in mm-Wave technology is considered costly and difficult in fabrication of complex structure. A 3D printing technology gives more flexibility and versatility with environment friendly that could produce low cost and lightweight devices.

A 3D printed horn antenna is firstly presented in 2005 by using stereolithography apparatus (SLA) technique [9], with average gain of $12 \mathrm{dBi}$. A non-metal 3D printed horn for W-band (75-110) $\mathrm{GHz}$ is introduced in [3], which is fabricated into two parts, then metal plated and assembled. A full 3D metal printed horn antenna is described by [10] for Ku-band using SLM metal printed technique. Recent studies showed a comparable performance of metal 3D printed mm-Wave passive devices printed by EBM metal 3D printing techniques for F-band and K-band [11-13].

In this paper, a 3D metal printed horn antenna prototype is demonstrated using a new 3D printing technique. Section 2 describes the design steps and the fabrication process of the proposed horn antenna for Ka-band. Section 3 discusses the performance and the measurement responses of the printed horn. Section 4 summaries the paper.

\section{RESEARCH METHOD}

The design process of the horn antenna parts; waveguide and horn aperture are presented in this section. A gain of $15 \mathrm{dBi}$ is aimed to achieve and used in the calculating of the size of horn aperture. Figure 1 shows the standard design parameters for a rectangular waveguide horn antenna and standard waveguide size.

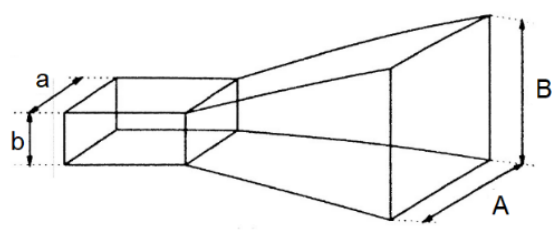

(a)

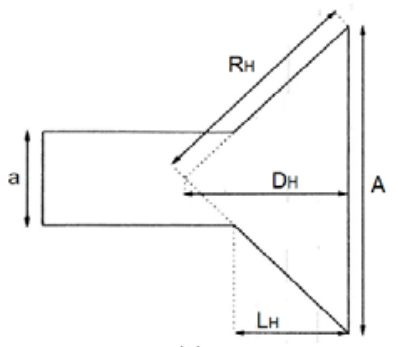

(c)

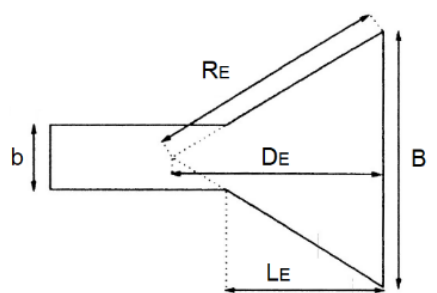

(b)

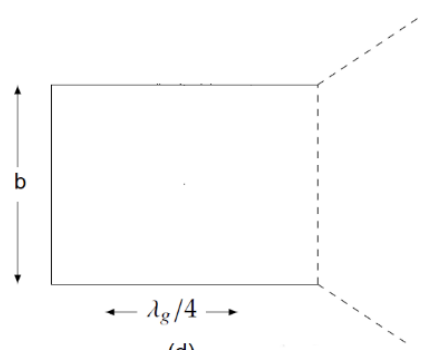

(d)

Figure 1. Standard horn structure and waveguide feed, (a) 3D model of horn shape, (b) horn shape from side, (c) horn shape from top, (d) waveguide feed from side [14]

To calculate the horn dimensions as in Figure 1, the following Equations from [14] are used. The standard WR-28 waveguide size is selected with inner dimensions of $(a \times b=7.112 \times 3.556) \mathrm{mm}$ to design the waveguide part.

$$
\begin{aligned}
& G_{l}=10^{G d B i / 10} \\
& A=0.096 a G l^{0.232}+0.24 \lambda G l^{0.503}-0.193 b
\end{aligned}
$$




$$
\begin{aligned}
& R_{H}=A \sqrt{\frac{1}{A}+\left(\frac{A}{3 \lambda}\right)^{2}} \\
& L_{H}=(A-a) \sqrt{\left(\frac{R H}{A}\right)-\frac{1}{4}} \\
& D_{H}=\sqrt{R H^{2}+\left(\frac{A}{2}\right)^{2}} \\
& B=\frac{1}{2}\left[b+\sqrt{b^{2}}+8 L H \lambda\right] \\
& R_{E}=\frac{B}{2} \sqrt{1+\left(\frac{B}{\lambda}\right)^{2}} \\
& L_{E}=(B-b) \sqrt{\left(\frac{R E}{B}\right)^{2}-\frac{1}{4}} \\
& D_{E}=\sqrt{R E^{2}+\left(\frac{B}{2}\right)^{2}}
\end{aligned}
$$

The guided wavelength for the proposed horn antenna is calculated by the following Equation [15]. By substituting the wavelength in free space $\lambda_{0}=75 \mathrm{~mm}$, the cut-off frequency of $26.4 \mathrm{GHz}$, and the centre frequency of $33.25 \mathrm{GHz}$, the guided wavelength is $\lambda g=124.12 \mathrm{~mm}$.

$$
\lambda_{g}=\frac{\lambda 0}{\sqrt{1-\left(\frac{f c}{f}\right)^{2}}}
$$

\begin{tabular}{|c|c|c|}
\hline \multicolumn{3}{|c|}{ Horn antenna parameters at ka band and $15 \mathrm{~dB}$ horn gain } \\
\hline Parameters & Calculated (mm) & Optimized (mm) \\
\hline $\mathrm{A}$ & 18.6 & 20 \\
\hline B & 12.7 & 14.6 \\
\hline $\mathrm{a} \times \mathrm{b}$ & $7.112 \times 3.556$ & $7.112 \times 3.556$ \\
\hline $\mathrm{L}_{\mathrm{H}}$ & 13 & 15.6 \\
\hline $\mathrm{R}_{\mathrm{H}}$ & 34 & 37 \\
\hline $\mathrm{D}_{\mathrm{H}}$ & 24 & 27 \\
\hline $\mathrm{L}_{\mathrm{E}}$ & 10 & 12.3 \\
\hline $\mathrm{R}_{\mathrm{E}}$ & 15 & 14.5 \\
\hline$D_{E}$ & 18.9 & 18.6 \\
\hline
\end{tabular}

A gain of $15 \mathrm{dBi}$ is chosen for this horn, so the linear value is $G l=31.62$. The value is substituted in (1). Thus, the dimension of the proposed horn is obtained through the above (2-9). The calculated and optimized values of the propose horn are summarized in Table 1. The proposed horn antenna and a 3D model of this antenna is found in Figure 2.

Table 1. The calculated and optimized parameters of proposed horn antenna at ka-band

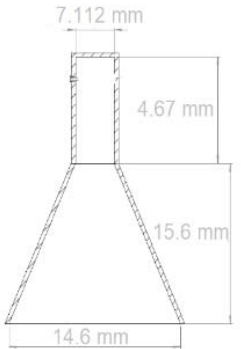

(a)

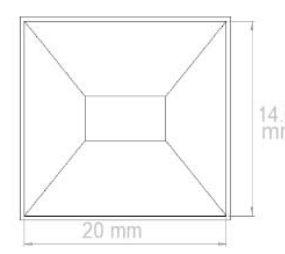

(b)

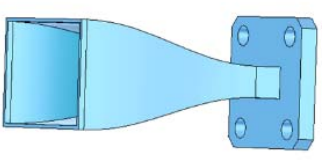

(c)

Figure 2. Final dimensions of proposed horn antenna and $3 \mathrm{D}$ view of horn, (a) side view shape, (b) front view horn, (c) 3D model of horn in CST software

$3 D$ printed horn antenna using direct metal laser melting technique for millimetre ... (Muataz W. Sabri) 
The proposed horn antenna is fabricated by metal 3D EOS M280 printer. The process involves of laser melting the metal powder into thin layers (about 20-60 $\mu \mathrm{m}$ ) and the prototype is constructed layer by layer, whereas the accuracy applied is within $\pm 0.05 \mathrm{~mm}$. Figure 3 shows the components of DMLM printer. The material used in the fabrication process is ALSi9. Which is in the form of metal powder. Generally, this material is cast-off with requirements of high conductivity for electronics devices.

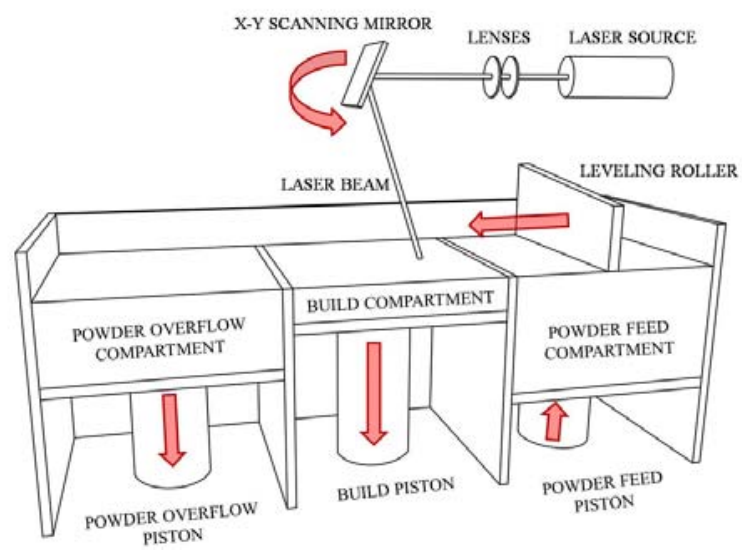

Figure 3. The DMLM 3D printing machining [6]

To provide a strong mechanical structure for the model, a thickness of $0.7 \mathrm{~mm}$ is chosen. The proposed horn is printed with flange together to able the measurement process. The prototype of $3 \mathrm{D}$ printed horn is shown in Figure 4. The measurement is performed using Vector Network Analyzer (R\&S®ZNB40).

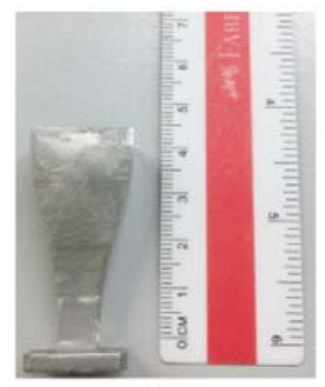

(a)

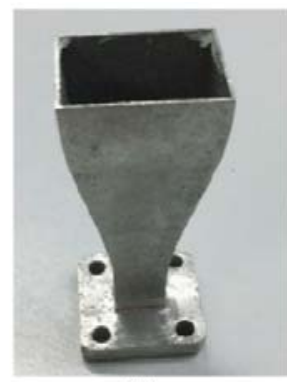

(b)

Figure 4. The printed horn antenna, (a) Front view, (b) Top view

\section{RESULTS AND ANALYSIS}

A two WR-28 coaxial-waveguide adaptors are used in the measurements process. The separation distance between the source antenna and test model is selected to be $50 \mathrm{~cm}$.

\subsection{Measured and simulated results analysis}

Figure 5 shows the measurement setup for the printed horn. Simulation results showed that the reflection coefficient, $\mathrm{S}_{11}$ is below $-10 \mathrm{~dB}$ for the range of ka band, with value of $-23.65 \mathrm{~dB}$ at $30 \mathrm{GHz}$. The gain values vary from 14.5-17.5 dB, with a horn gain of $15.3 \mathrm{~dB}$ at frequency of $30 \mathrm{GHz}$. The measured reflection coefficient $\mathrm{S}_{11}$ of $-21.32 \mathrm{~dB}$ at $30 \mathrm{GHz}$ is obtained. While the measured gain value is $14.31 \mathrm{~dB}$, a bit difference compared to the simulation one by $(-0.98) \mathrm{dB}$ at frequency of $30 \mathrm{GHz}$. Figure 6 shows the performance of the printed horn antenna in terms of S-parameters and gain. The discrepancies pattern appeared in the measurements may come from the surface roughness and dimensional tolerance of the printed horn antenna. 


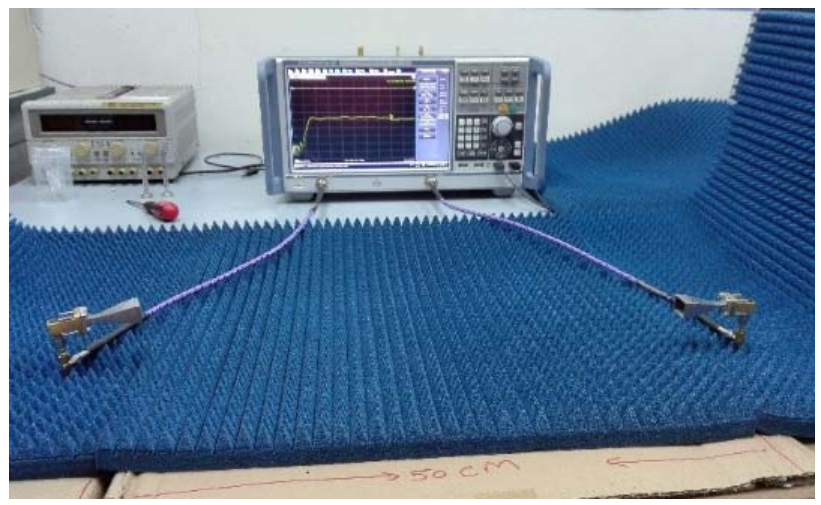

Figure 5. The measurements setup of 3D printed horn antenna for reflection coefficient and radiation pattern at Ka- band

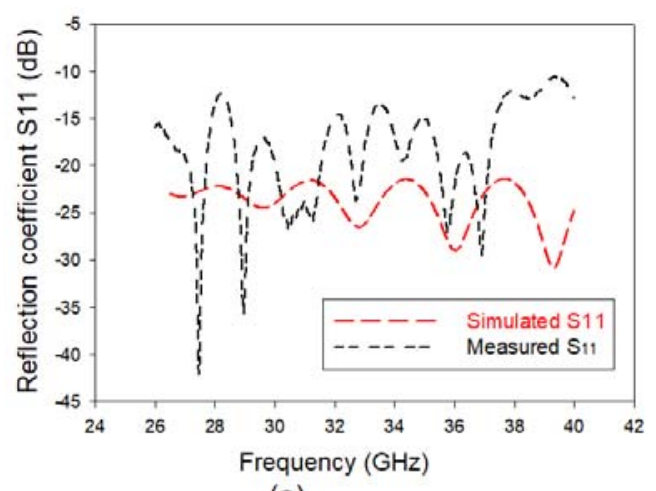

(a)

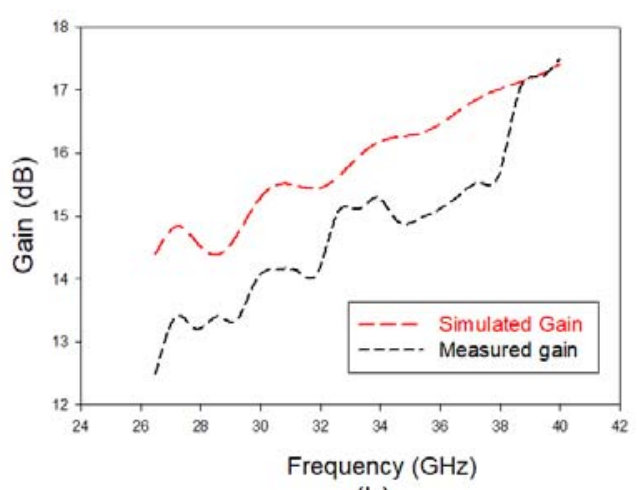

(b)

Figure 6. The performance responses of 3D printed horn antenna, (a) reflection coefficient response, (b) gain of horn antenna

Figure 7 shows the performance of the radiation pattern of the printed horn. The main lobe direction is in the positivize $\mathrm{Z}$-axis with directivity of $15.3 \mathrm{dBi}$ at $30 \mathrm{GHz}$. the side lobes level in E-plane is about -12.2 $\mathrm{dB}$, while the side lobes in H-plane is lower than E-plane. The $3 \mathrm{~dB}$ beamwidth is about $28^{\circ}$ degree. The measured radiation pattern has main lobe direction shifted by $2.5^{\circ}$ degree and a low side lobes value compared to the simulation one.

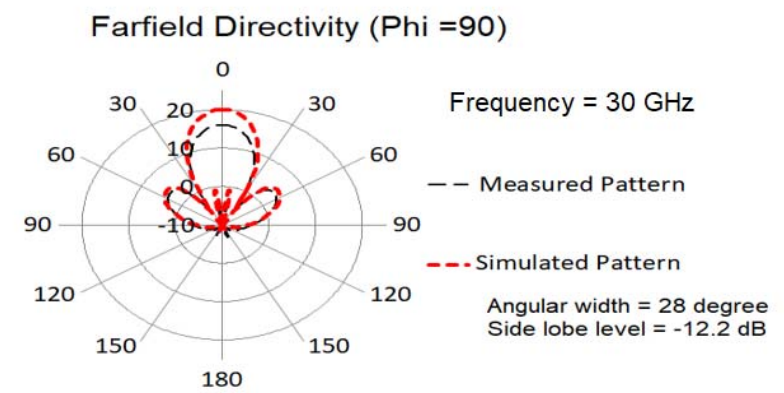

Theta / Degree vs. dBi

Figure 7. Radiation pattern of proposed 3D printed horn antenna 


\subsection{Surface roughness and metallization impact on $3 \mathrm{~d}$ printed horn analysis}

The profiling on the prototype of 3D printed horn is measured by using (FE-SEM) field emission scanning electron microscope. At $50 \mathrm{~mm}$ depth scale, a surface roughness is observed at the inner surface of the printed horn, which effects on reducing the gain (as in Figure 8). In the same time, several cracks are appeared on the open area of WR-28 printed waveguide due to the fabrication unperfect deployed layers. The outer surface of the printed horn showed a smooth surface compared to the inner one.

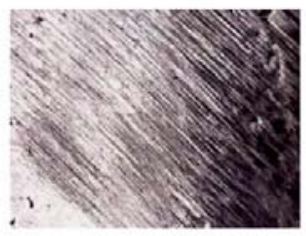

(a)

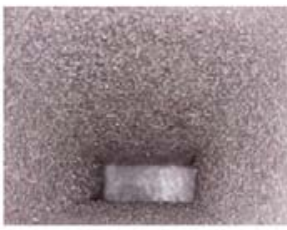

(b)

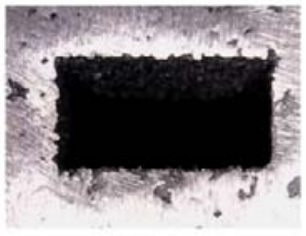

(c)

Figure 8. Profiling of 3D printed horn antenna at $50 \mathrm{~mm}$, (a) outside surface of horn, (b) surface inner side of the horn, (c) cracks appeared in the flange area

The metal layer of the 3D printed horn is illustrated in Figure 9 with at scale of $10 \mu \mathrm{m}$. It is observed that the metal layer is deployed well within the calculated skin depth. The layer is used to measure the thickness and skin depth of the printed structure.

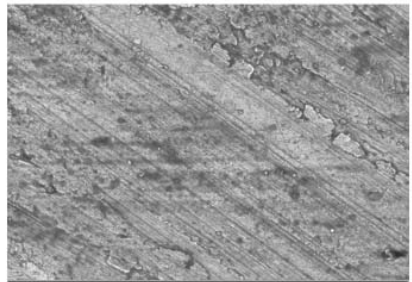

(a)

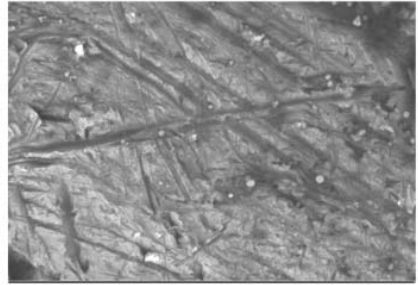

(b)

Figure 9. Metal layer of 3D printed horn at $10 \mu \mathrm{m}$, (a) skin depth of $0.2 \mathrm{~mm}$ and well distributed (outside surface) (b) slightly cracks in the skin depth of inner side of the horn

Table 2 shows the measured and calculated layer and skin depth for deployed material for the Kaband range. Table 3 compared this work with recent studies on 3D printed horn antenna.

Table 2. The layers of the 3D printed horn prototype

\begin{tabular}{|c|c|c|c|}
\hline \multicolumn{3}{|c|}{ Skin depth and metal thickness of ALSi9 material } & \multirow[b]{2}{*}{$\begin{array}{c}\text { Measured depth } \\
(\mu \mathrm{m})\end{array}$} \\
\hline $\begin{array}{c}\text { Frequncy } \\
(\mathrm{GHz})\end{array}$ & $\begin{array}{c}\text { Skin depth } \\
(\mu \mathrm{m})\end{array}$ & $\begin{array}{l}\text { Metal thickness } \\
(\mu \mathrm{m})\end{array}$ & \\
\hline 26.5 & 0.504 & 5.05 & \pm 0.453 \\
\hline 30 & 0.473 & 5.05 & \pm 0.415 \\
\hline 40 & 0.410 & 5.05 & \pm 0.395 \\
\hline
\end{tabular}

As mentioned earlier, the discrepancies pattern occurred in the measurement process may be caused by surface roughness or dimensional tolerance of the printed horn. To elaborate these discrepancies pattern, a simulation is done on the proposed horn antenna taking in consideration the effects of surface roughness and dimensional tolerance factors. Then an overlay between simulated results and measured results is plotted as shown in Figure 10. The simulated reflection coefficient $S_{11}$ (with surface roughness) is similar to the measured results (as in Figure 10(a)). Which is caused by surface roughness and dimensional tolerance around the feed. 
The simulated gain (in Figure 10(b)) is slightly differed from the measured gain and experienced a $1.2 \mathrm{~dB}$ loss at $30 \mathrm{GHz}$ compared to the original simulated gain in Figure 6(b). This is due to dimensional tolerance in the width of the horn aperture and surface roughness. Overall, the effects of surface roughness and dimensional tolerance applied in the simulation produce similar results to the measured one.

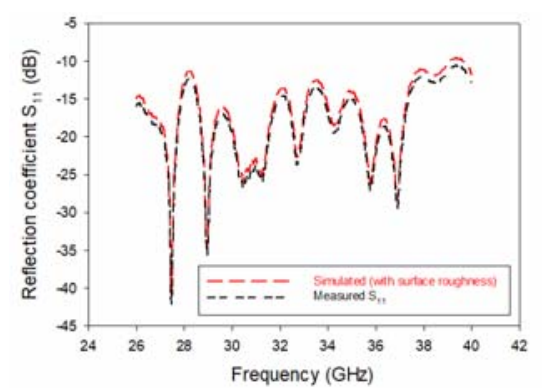

(a)

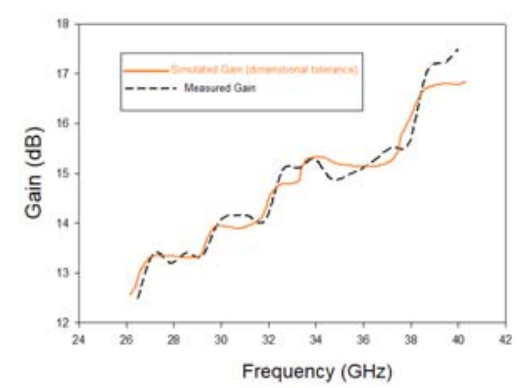

(b)

Figure 10. Comparison between the measured responses and the simulated results with surface roughness and dimensional tolerance added to the simulation (a) reflection coefficient response, (b) gain of horn antenna

Table 3. Comparison of this work with recent related studies on 3D printed horn antenna

\begin{tabular}{cccccc}
\hline Studies & Technology & Material & Coating process & Gain $(\mathrm{dB})$ & Frequency range $(\mathrm{GHz})$ \\
\hline Ref [16] & FDM & ABS & Copper $(\mathrm{Cu})$ & $15-18$ & $26.5-40$ \\
Ref [17] & SLM & Copper & No process & 8.1 & $26.5-40$ \\
Ref [18] & SLM & Aluminum alloy & No process & $12-16$ & K-band \\
This work & DMLM & ALSi9 & No process & $13-17$ & $26.5-40$ \\
\hline
\end{tabular}

\section{CONCLUSION}

A fully metal 3D printed horn is introduced at Ka-band in this paper. The prototype is fabricated by using new technique of 3D printing technology. The direct metal laser Melting (DMLM) printing technology using ALSi9 metal powder is used to provide strong structure and low cost. The performance of the 3D metal printed agreed well with the simulated results. The measured reflection coefficient is less than $-10 \mathrm{~dB}$ over the bandwidth, and the measured directivity obtained is $14.31 \mathrm{dBi}$ at $30 \mathrm{GHz}$. The prototype has a weight of $130 \mathrm{~g}$, which is lighter than any commercial standard horn antenna at Ka-band. This 3D printed horn antenna prototype can be proposed for Ka-band applications.

\section{ACKNOWLEDGEMENTS}

The Authors would like to express their appreciations to the support of the research under Advanced RF \& Microwave Research Group, the Research Management Centre (RMC), School of Electrical Engineering, School of Postgraduate (SPS), Universiti Teknologi Malaysia (UTM), and grant no 04G72, 13J86, 04G68 and 04G65.

\section{REFERENCES}

[1] Dimitriadis A.I., Favre M., Billod M., de Rijk E., "Design and fabrication of a lightweight additivemanufactured Ka-band horn antenna array," 10th European Conference on Antennas and Propagation (EuCAP). Davos, pp. 1-4, 2016.

[2] Zhang B, Chen W., Wu Y., Ding K., Li R., "Review of 3D Printed Millimeter-Wave and Terahertz Passive Devices," International Journal of Antennas and Propagation, pp. 1-10, 2017.

[3] Timbie P., Grade J., Weide D., Maffie B, Pisano G. "Stereolithographed MM-wave corrugated horn antennas," International Conference on Infrared Millimeter, and Terahertz Waves. Huston, pp. 1-3, 2011.

[4] Gibson I., Rosen D., Stucker B. Additive manufacturing technologies rapid prototyping to direct digital manufacturing. Boston. Springer, pp. 125-127, 2010.

[5] Hoel K.V, Kristoffersen S., Moen J., Kjelgård K., Lande T., "Broadband antenna design using different 3d printing technologies and metallization processes," 2016 10th European Conference on Antennas and Propagation (EuCAP). Davos, pp. 1-5, 2016. 
[6] Palumbo B., Del re F., Martorelli M., Lanzotti A., Corrado P., "Tensile Properties Characterization of AlSi10Mg Parts Produced by Direct Metal Laser Sintering via Nested Effects Modeling," Materials, [[vol. 10(2), pp. 144, 2017.

[7] Chieh C.J., Dick B. Loui S., Rockway J., "Development of a Ku-band corrugated conical horn using 3-D print technology," IEEE Antennas Wirel. Propag. Lett, vol. 13, pp. 201-204, 2014.

[8] Genc A., Basyigit I., Goksu T., Helhel S., "Investigation of the performances of X-Ku band 3D printing pyramidal horn antennas coated with the different metals," 2017 10th International Conference on Electrical and Electronics Engineering (ELECO), Bursa, 2017.

[9] Schulwitz L. and Mortazawi A., "A compact dual-polarized multibeam phased-array architecture for millimeter-wave radar," IEEE Transactions on Microwave Theory and Techniques, vol. 53(11), pp. 35883594, 2005.

[10] Zhang B., Zhan Z., Cao Y., Gulan H., Linnér P., Sun J., Zwick T., Zirath H., "Metallic 3D printed antennas for millimeter- and submillimeter-wave applications," IEEE Trans. Terahertz Sci. Technol, vol. 6(4), pp. 592-600, 2016.

[11] Gordon A.J., Novotny D., Francis M., Wittmann R., Butler M., Curtin A., Guerrieri J., Periasamy L., Gasiewski A., "All metal, 3-D-printed CubeSat feed horn: An assessment of performance conducted at 118.7503 GHz using a robotic antenna range," IEEE Antennas Propag. Mag, vol. 59(2), pp. 96-102, 2017.

[12] Ignatenko M., Simakauskas B., Notaros M., "Filipovic D. A phase center-stabilized K/Ka/V band linearly-polarized horn for Luneberg lenses," IEEE Antennas Wirel. Propag. Lett, vol. 16, pp. 2726-2729, 2017.

[13] Zhang B., Linnér P., Karnfelt C., Tarn P., Södervall U., Zirath H., "Attempt of the metallic 3D printing technology for millimeter-wave antenna implementations," In Proceedings of the Asia-Pacific Microwave Conference (APMC). Nanjing, pp. 1-3, 2015.

[14] Granet G. Modern antenna handbook. John Wiley \& Sons. 1, pp. 157-200, 2008.

[15] Carr J.J and Hippisley G.W. Practical Antenna Handbook. McGraw-Hill Companies. 5, pp. 447-489, 2012.

[16] Haohan Y., Shilpi S., Rashaunda H., Solyman A., and Duncan, M.F., "Ka band 3D printed horn antennas," 2017 Texas Symposium on Wireless and Microwave Circuits and Systems (WMCS). Texas, 2017.

[17] Eduardo A., Justin N., Thomas M., and Nathan B., "Metallic 3D printed Ka-band pyramidal horn using binder jetting," 2016 IEEE MTT-S Latin America Microwave Conference (LAMC). Puerto Vallarta, 2016.

[18] Bing Z., Li W., Yauping Z., Yang Y., Huacheng Z., and Yanjie W., "A 3D Printed Aluminum Alloy KBand Square Stepped Doubled Ridged Horn Antenna," 2018 IEEE International Conference on Computational Electromagnetics (ICCEM). Chengdu, pp. 1-3, 2018. 